\title{
Detection of vertical surface cracks in unidirectional carbon fibre composites with an infrared line scanning technique
}

\author{
by J. Varis, R. Lehtiniemi and J. Rantala
}

Department of Physics, P.O. Box 9, FIN-00014 UNIVERSITY OF HELSINKI, Finland

Nokia Research Center, P.O.BOx 407, FIN-00045 NOKIA GROUP, Finland

\begin{abstract}
Crack detection in carbon-fibre-reinforced-composites was studied by using an infrared, linescanner-based, nondestructive technique. In a unidirectional composite, $20 \mathrm{~mm}$ long and $0.2 \mathrm{~mm}$ wide artificial cuts were made to simulate vertical surface cracks. In order to estimate the detectability of the cracks, finite difference calculations were carried out. The numerical calculations estimated that surface cracks with depths down to $80 \mu \mathrm{m}$ were possible to be detected. In the experiments, the composite was heated with a radio frequency induction coil, and the surface temperature of the composite was monitored with the infrared line scanner. In the experiments, $160 \mu \mathrm{m}$ deep vertical surface cracks were observed.
\end{abstract}

\section{Introduction}

Vertical cracks are among the typical defects found in carbon fibre reinforced composites (CFRC). This type of defect is a very serious problem, especially with unidirectional composites, in which fiber breakage or matrix cracking can totally ruin the composite's ability to carry the mechanical loads it was designed for. Vertical cracks are also very difficult to detect with the conventional thermal NDT techniques, applying heat in the direction normal to the composite surface.

A solution is to use a source that generates heat flow in the lateral directions as well. Such techniques include "mirage" [1] and "flying spot" [2,3] methods, which have been applied for vertical crack detection successfully. Another possible method might be the use of scanned line source demonstrated earlier by Hartikainen [4]. Delamination [5] and impact damage detection [6] has also been shown earlier with the infrared line scanning technique. In principle, a vertical crack parallel to the line source should hinder the heat flow enough for a detectable heat build up to be formed.

\section{Numerical model}

The carbon fibre composite consisted of nine $80 \mu \mathrm{m}$ thick unidirectional plies. The laminate was covered from both sides with woven 2-D protective skins, giving the laminate a total thickness of approximately $800 \mu \mathrm{m}$. In the laminate, several $20 \mathrm{~mm}$ long and $0.2 \mathrm{~mm}$ wide cuts were made to simulate vertical surface cracks. The depth of the cracks from the surface ranged from one to five plies.

Finite difference computations, as described by Varis et al. [7], were performed to estimate the effect of the cracks on the surface temperature of the composite when a scanned line heat source was used. The model (Fig.1) consisted of $40 \times 240 \times 15$ grid points, corresponding to a physical composite size of $30 \mathrm{~mm} \times 50 \mathrm{~mm} \times 0.8 \mathrm{~mm}$. The grid was divided into three layers, making it possible to have two different crack depths of $80 \mu \mathrm{m}$ and $400 \mu \mathrm{m}$. Thus, the first layer consisted of the top ply, and the second and the third had four plies each. The thermal characteristics were: density $1400 \mathrm{~kg} \mathrm{~m}^{-3}$, specific heat $935 \mathrm{~J} \mathrm{~kg}^{-1} \mathrm{~K}^{-1}$, thermal conductivity in the $x$-direction $11.1 \mathrm{~W} \mathrm{~m}^{-1} \mathrm{~K}^{-1}$, and thermal conductivity in the $y$ - and z-directions $0.87 \mathrm{~W} \mathrm{~m}^{-1} \mathrm{~K}^{-1}$. The $20 \mathrm{~mm}$ long crack was simulated by placing thermal contact resistances, $R_{c}$, between two $y z$ grid point planes. The values used were $R_{c}=10^{-2} \mathrm{~m}^{2} \mathrm{KW}^{-1}$. 
The heating line was parallel to the crack, and it was moving along the $y$-direction (i.e. the direction of the fibres) at a velocity of $2 \mathrm{~mm} / \mathrm{s}$. A very wide source of $5.7 \mathrm{~mm}$ with a power of $10 \mathrm{~W}$ was used for simulating the actual source applied in the experiments.

As a result of the numerical computations, three surface temperatures, $T$, profiles were obtained (Fig. 2a). In the case of a sample with a crack, the curves have a clear step $2.1 \mathrm{~mm}$ away from the centre on the front edge of the heating line. The step is larger the deeper the crack is. The curve for a faultless case $\left(R_{c}=0\right)$ has no discontinuity. The temperature difference between a faultless sample and one with a crack is also largest at the location of the step, suggesting an optimal point for the detection. Normally, the detection point is behind the heat source, which can be applied here as well. However, the temperature increase caused by the crack vanishes shortly after the heating line, which should be taken account in the experimental setup. At the optimum point, the temperature increase caused by the crack is resolvable in both the cases.

Fig. $2 b$ shows a three-dimensional surface temperature difference, $\Delta T$, map obtained by subtracting the surface temperature values for a faultless sample from the corresponding values for a sample with a $400 \mu m$ deep crack. The temperature values were computed at the optimum detection point. Fig. 2 b shows a clear temperature increase on the first edge of the crack, whereas on the second edge the temperature is much lower than in the surroundings. The thermal conductivity is twelve times higher in the direction of the fibers (the $y$-direction) than in the other two directions. Therefore, the heat is mostly transferred towards the crack, even though the heating line has not yet reached it. As the crack stops the heat transfer further, the temperature starts increasing near the first edge of the crack. When the heat source has moved on the other side of the crack, the fibres transfer the heat away from the crack more effectively. Consequently, no heat build up is observed on the second edge of the crack.

\section{Measurement setup}

The measurements were carried out using an infrared line scanning system (Fig. 3) described earlier by Lehtiniemi and Hartikanen [5]. In the system, a radio frequency induction coil was used for heating. The size of the coil was $5.7 \mathrm{~mm} \times 50 \mathrm{~mm}$, and the estimated heating power was $10 \mathrm{~W}$. The composite was moved perpendicularly to the coil using a stepping motor stage. Simultaneously, the surface temperature of the composite was monitored with an infrared line scanner. The scanner consisted of a $25 \mu \mathrm{m} \times 25 \mu \mathrm{m} \mathrm{HgCdTe}$ detector, a $25 \mathrm{~mm} \mathrm{Ge}$ lens, and a deflection mirror. The system sampled the surface temperature of the composite in 180 points alongside the heating coil. 280 image lines were recorded while the composite was translated by means of the stepping motor stage. The image lines were combined into a pseudo colour image by using a microcomputer. The same computer controlled the stepping motor stage, the deflection mirror, and the data acquisition from the detector. The measurement time of one pseudo colour frame was $6 \mathrm{~s}$.

\section{Results}

Two thermal images obtained with the infrared line scanner are shown in Figs. $4 a$ and $\mathrm{b}$. The size of the imaged areas is about $50 \mathrm{~mm} \times 30 \mathrm{~mm}$, and the heating coil moved from left to right in the images. The first one is an image of a $160 \mu \mathrm{m}$ deep crack, and the second one shows a $400 \mu \mathrm{m}$ deep crack. In both the cases, the cracks are resolved as the hotter (white) areas in the middle of the thermal images. The heat signature is stronger in the case of the deeper surface crack, which is consistent with the numerical estimates. For practical reasons, the detection point was behind the heat source, and therefore, the observed temperature increase caused by the cracks was not the greatest possible. For this reason, the shallower crack in Fig. $4 a$ is barely observable. Also, shallower cracks than $160 \mu \mathrm{m}$ were not observed.

In the images, the finer structure of the protective skins can also be seen, even though the use of wide heat source tends to deteriorate the spatial resolution. This is a typical 
example of the power of a selective heating method as the radio frequency induction, which heats only the electrically conductive carbon fibres, leaving the polymer matrix relatively cool. This eliminates non-wanted components from the images. Thus, the selectivity factor compensates for the loss of resolution, and as a result, the interesting details are still resolvable with good contrast.

\section{Conclusions}

The results show that the infrared line scanning technique is a potential candidate for detecting vertical cracks in carbon fibre reinforced composites. The lateral heat flow generated by the moving line heat source is stopped by the vertical cracks, and at least in the case of surface cracks, they can be detected. In this respect, the experimental results agree with the numerical calculations. For practical reasons, the detection point cannot be placed where the numerical results suggest. As a result, shallower than $160 \mu \mathrm{m}$ deep cracks were not observed, although in the numerical results an $80 \mu \mathrm{m}$ deep crack was resolvable. Closed vertical cracks have not been studied here. The use of a selective heating method, such as the radio frequency induction here, has proven out to be fruitful in the case of CFRC as well. Only the carbon fibres, as electrically conductive, are heated in the process. As a result, high contrast thermal images are obtained.

\section{REFERENCES}

[1] RANTALA (J.), JAARINEN (J.), and HARTIKAINEN (J.) - Appl. Phys. A 50, 1990, p. 465.

[2] KUBIAK (E. I.) - Appl. Opt. 7, 1968, p. 1734

[3] WANG (Y. Q.), KUO (P. K.), FAVRO (L. D.), and THOMAS (R. L.). - Review of Progress in QNDE, Vol. 9A, eds. D. O. Thompson and D. E. Chimenti, New York, Plenum Press, 1990, p. 511.

[4] HARTIKAINEN (J.) - Rèv. Sci. Instrum. 60, 1989, p. 1334.

[5] VARIS (J.), RANTALA (J.), and HARTIKAINEN (J.) - NDT\&E Intern. 29, 1996, p. 371.

[6] LEHTINIEMI (R.) and HARTIKAINEN (J.) - Rev. Sci. Instrum. 65, 1994, p. 2099.

[7] VARIS (J.), RANTALA (J.), and HARTIKAINEN (J.). - Res. Nondestr. Eval. 6, 1995, p. 69.

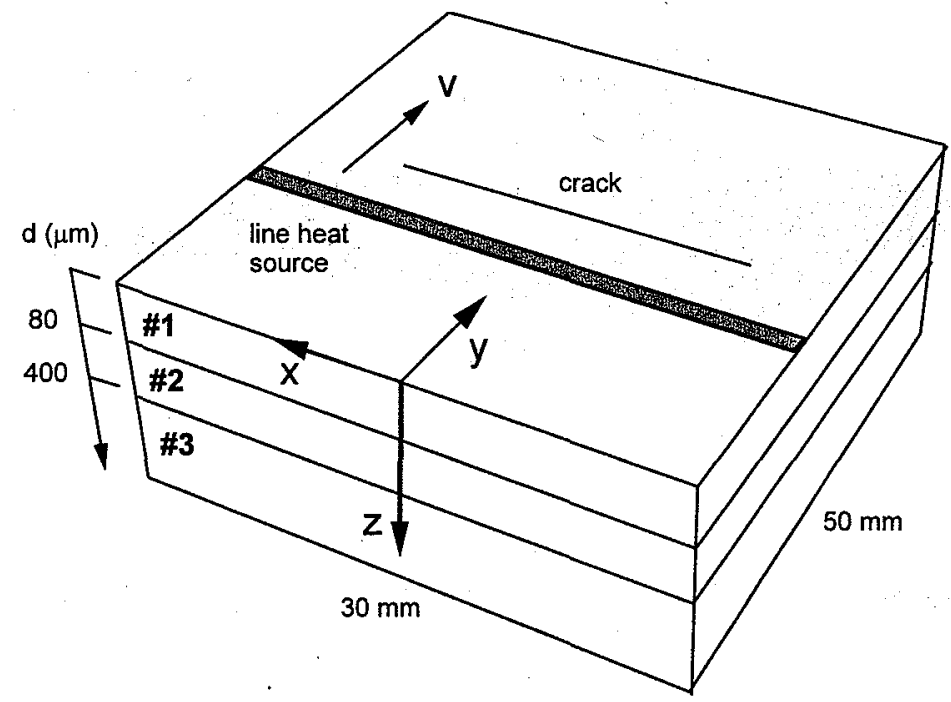

Fig. 1. Numerical model used in the finite difference computations 
http://dx.doi.org/10.21611/qirt.1998.007

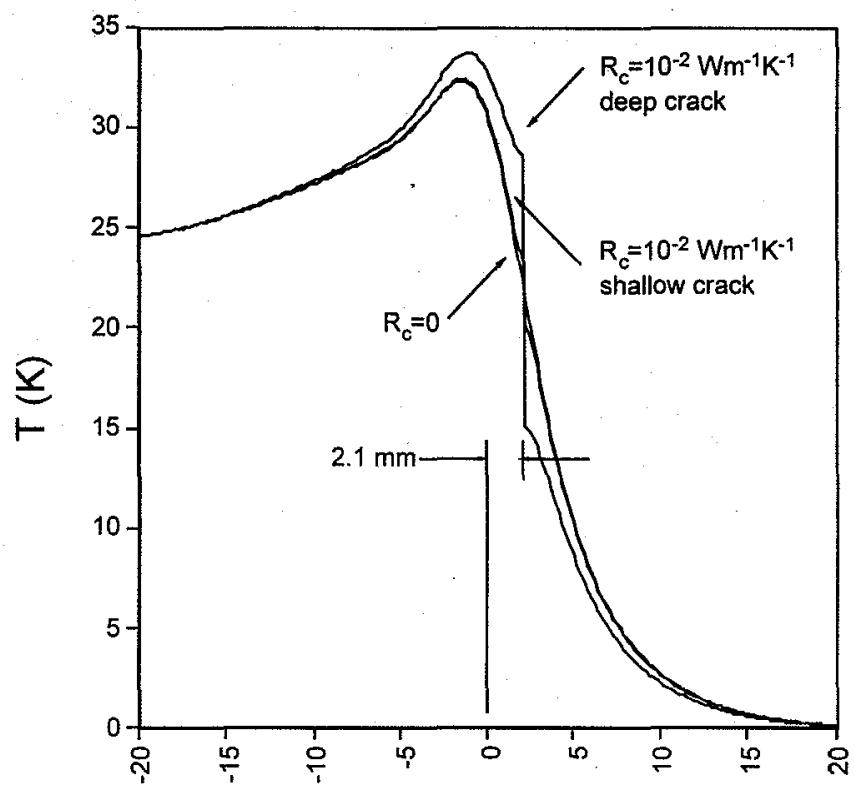

Distance from heat source center $(\mathrm{mm})$

Fig. 2a. Surface temperature profiles for a composite with no crack, a $80 \mu \mathrm{m}$ deep crack, and a $400 \mu \mathrm{m}$ deep crack

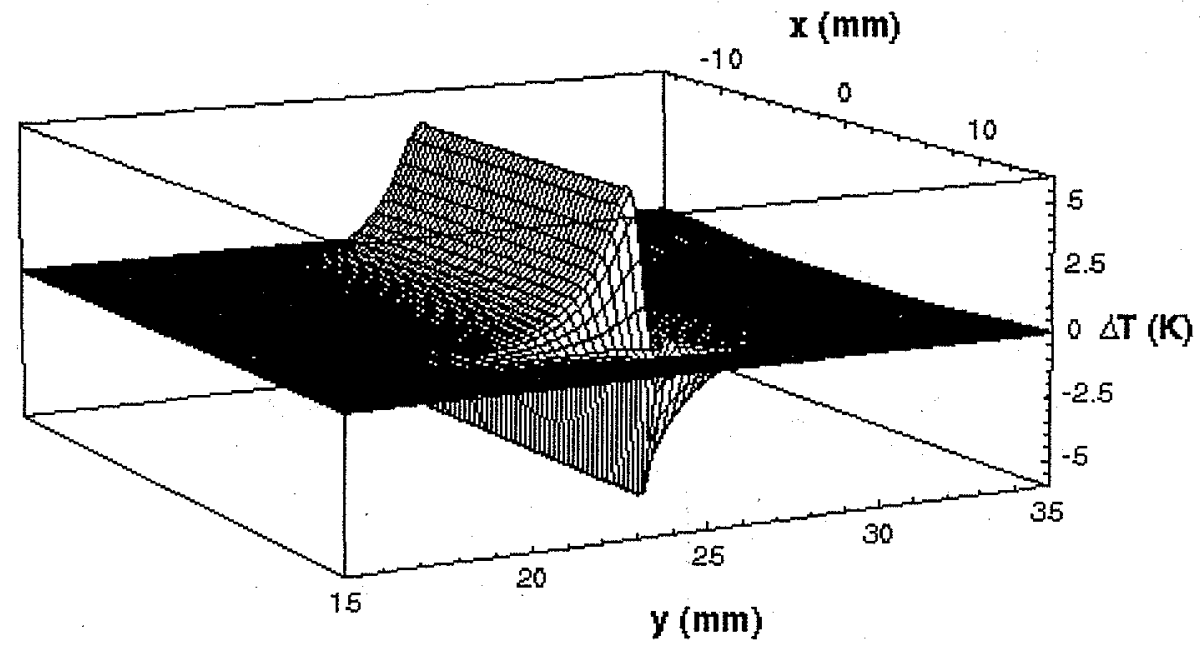

Fig. 2b. Three-dimensional temperature difference map for a composite with a $400 \mu \mathrm{m}$ deep crack 
http://dx.doi.org/10.21611/qirt.1998.007

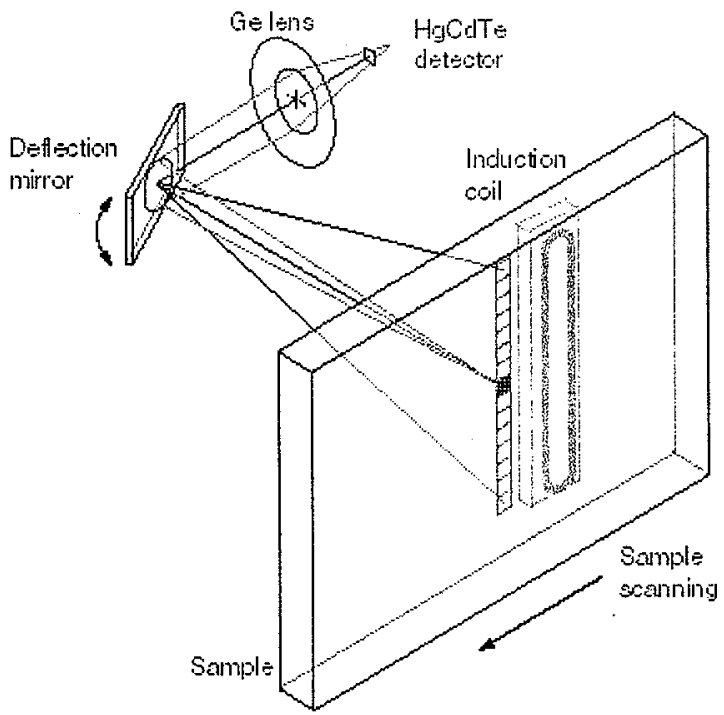

Fig. 3. Measurement system

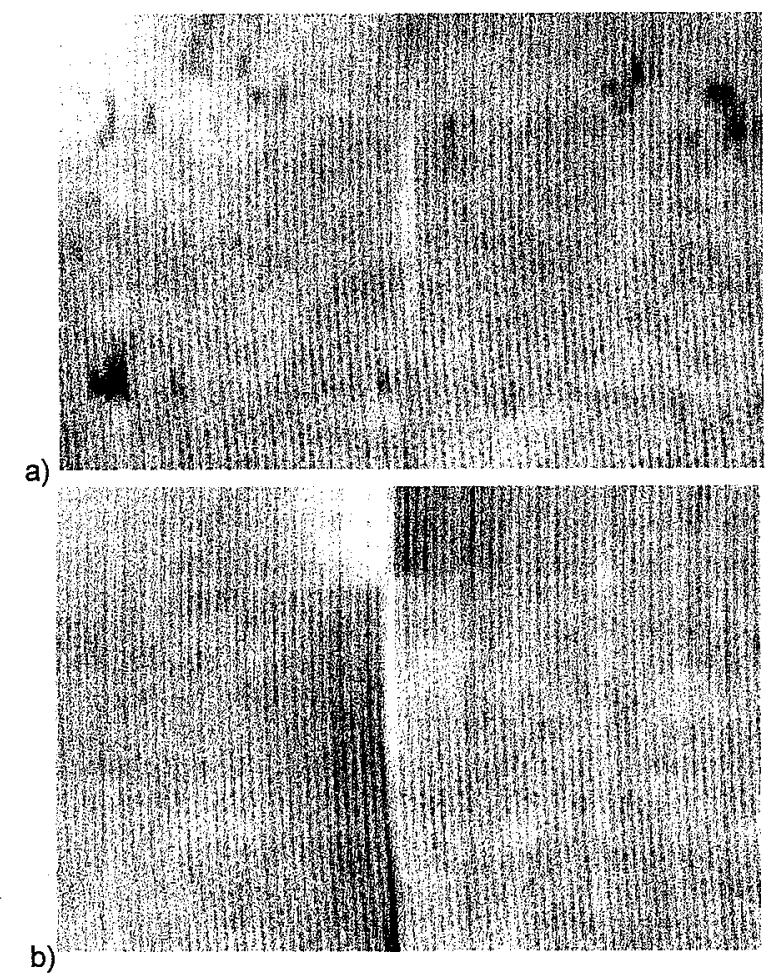

Fig. 4. Thermal images of vertical cracks having depths of a) $160 \mu \mathrm{m}$ and b) $400 \mu \mathrm{m}$ 